\title{
Primary Refractory
}

National Cancer Institute

\section{Source}

National Cancer Institute. Primary Refractory. NCI Thesaurus. Code C70604.

Disease status just prior to the start of the preparative regimen for hematopoietic stem cell transplantation (HSCT): Primary refractory refers to never achieving a complete remission (CR) from any therapy and also not being in partial remission (PR) at the time of the last evaluation prior to HSCT. PR could have been achieved at some point, but the recipient is no longer in PR. 